\title{
CORRESPONDENCE
}

\author{
Dangers of transporting sick children by \\ A Raffles, MRCP, and Barbara Stewart, BA . 322 \\ Payments to doctors and the \\ responsibilities of ethics committees \\ A L Diamond, LLM, and Sir Kenneth \\ Robinson, PC; Jennifer Cousins ....... 322 \\ Convaid: for anyone who is speech \\ impaired? \\ T Steiner, MB, and others; F Wolff . . . . 323 \\ Head injuries in adults \\ $\mathrm{K} T$ Evans, FRCR, and others; G T Watts, \\ FRCS ...................... 323 \\ Professionals' attitude to childbirth \\ Hilary Cashman, PHD ............ 324 \\ Did the Mad Hatter have mercury \\ poisoning? \\ T M L Price, FRCP; R Lightwood, FRCP; \\ S H Goodacre, $M B$.............. 324
}

Long term domiciliary oxygen treatment

I $\mathbb{B}$ B Grant, FRCP .............. 325

Medical defence societies

P G T Ford, MRCGP; R A Haward, FFCM, and G J R Richardson, MRCPSYCH ..... 325

Ultrasonic diagnosis of portal

hypertension

M Cottone, $M D$, and others .......... 326

$A$ better deal for overseas doctors

S F Al Damluji, FRCP; M C K Chan, FRACP. 326

Entry to general practice training

$T$ Sweeney, MB, and others; J Roberts,

FRCGP $\ldots \ldots \ldots \ldots \ldots \ldots \ldots \ldots \ldots \ldots \ldots \ldots \ldots \ldots \ldots \ldots$

Hypertension and wellbeing

P Pacy, MRCP, and P Dodson, MRCP . . . . 327
Amiodarone: the experience of the past decade

Y Abramovici, MD, and others ....... 327

Drugs or oxygen for hypoxic cor pulmonale?

N K Burki, MRCP; P Howard, FRCP . . . . 328

Prevalence of chlorpropamide alcohol flushing

P G Wiles, MRCP, and others; S Ng Tang

Fui, MRCP, and others ........... 328

Securing preregistration posts

R Hall, FRCs, and others . . . . . . . . . 329

Development of a strategy for higher education

J P Payne, frarcs . . . . . . . . . . . 329

Correction: Junior doctors' hours of work

(Bristow) .................... 329

We may return unduly long letters to the author for shortening so that we can offer readers as wide a selection as possible. We receive so many letters each week that we have to omit some of them. Letters should be typed with double spacing between lines and must be signed personally by all their authors, who should include their degrees. Letters critical of a paper may be sent to the authors of the paper so that their reply may appear in the same issue.

Correspondents should present their references in the Vancouver style (see examples in these columns). In particular, the names and initials of all authors must be given unless there are more than six, when only the first three should be given, followed by et al; and the first and last page numbers of articles and chapters should be included.

\section{Dangers of transporting sick children by air}

SIR,-Squadron leader Richard Harding and Dr F John Mills warn in their book Aviation Medicine ${ }^{1}$ that patients who are transported by air may become acutely ill when subjected to the different physiological conditions of flight. Yet specialised medical expertise is not available in some countries, and critically ill children may need to be urgently transferred by air. Our hospital, Hillingdon Hospital, is close to London's Heathrow Airport, and we describe two children whose medical condition deteriorated as a direct result of flying.

A 10 month old Indian girl was born with cyanosis, and investigation showed that she had severe pulmonary stenosis with systemic pressures in the right ventricle and a right to left shunt at atrial level. She had no further treatment until she deteriorated with increasing cyanosis and heart failure. She was then transferred with only a nurse escort on a scheduled flight. Some five hours before arrival in London she became deeply cyanosed with laboured respiration, and she was given $100 \%$ unhumidified oxygen by face mask by a doctor who was a passenger. She continued to London and was transferred by ambulance to this hospital.

On arrival she was grossly cyanosed, plethoric, and had gasping respirations at a rate of 12 a minute. Cardiovascular examination showed a single second sound and a soft systolic ejection murmur in the pulmonary area. Blood pressure was unrecordable. A severe hypoxic episode was diagnosed. Resuscitation included intubation and manual ventilation. An initial intramuscular injection of morphine was given followed by intravenous morphine, propranolol, sodium bicarbonate, plasma, and an infusion of noradrenaline. A blood gas estimation showed a $\mathrm{pH}$ of $7 \cdot 0$, an oxygen pressure of $4 \mathrm{kPa}(30 \mathrm{~mm} \mathrm{Hg})$, a carbon dioxide pressure of $6 \mathrm{kPa}(45 \mathrm{~mm} \mathrm{Hg})$, a bicarbonate concentration of $16 \mathrm{mmol}(\mathrm{mEq}) / 1$, and a base deficit of $-8 \mathrm{mmol}(\mathrm{mEq})$. With treatment her cardiac output improved and she became more awake. She was transferred to the cardiothoracic centre where she underwent open valvotomy and has since done very well.

An 11 year old boy sustained a subdural haematoma after a road accident in which his parents were killed. After prolonged intubation and unsuccessful attempts at extubation a tracheostomy was performed. He was transferred to Britain unescorted on a scheduled flight for tracheal reconstruction. During the flight he developed increasing respiratory obstruction, and unhumidified $100 \%$ oxygen was given by a doctor passenger on the flight. He was transferred urgently to this hospital, where on arrival he was distressed and cyanosed, and had appreciable intercostal recession. He had a thick mucuous plug obstructing the tracheostomy tube. After lavage he recovered.

We present these two cases to highlight avoidable factors. In the first case the child was already hypoxaemic and polycythaemic with an appreciably reduced pulmonary blood flow, and yet she was exposed to a low ambient inspired oxygen due to the cabin pressure being maintained at a pressure equivalent to that at about $1800-2400 \mathrm{~m}$. The reduced oxygen pressure leads to a fall in alveolar oxygen and tissue hypoxia and a consequent fall in pulmonary blood flow due to acidosis. The low relative humidity, which decreases as the flight progresses, results in increased evaporative water loss and subsequent dehydration and makes worse the polycythaemia.

In the second case the dehydration combined with inadequate tracheostomy care led to increased mucuous plug formation and so obstruction. Treatment with humidified oxygen would have ameliorated the condition of both children, but the first case required a higher than normal alveolar oxygen pressure, which was unavailable on the flight.

Two further children with congenital heart disease who deteriorated on planes, one of whom died at the airport, have been seen by our unit within the last year. The deterioration and death could possibly have been avoided. We suggest that if a child with a low arterial oxygen pressure must fly a suitable face mask to deliver humidified oxygen must be provided and extra fluids must be given, as recommended by the Commission on Emergency Medical Services. ${ }^{2}$ Furthermore, we think cardiothoracic referral centres and airlines should give specific guidance for their patients.

Our thanks to Dr S M Tucker and Dr P Jaffe for allowing us to report children under their care.

ANDREW RAFFLES BARBARA STEWART

Hillingdon Hospital,

Uxbridge, 8 3N ' Harding RM, Mills FJ. Aviation medicine. London:
BMA, 1983.
' Commission on Emergency Medical Services. Medical
aspects of travel. $\mathscr{f} A M A 1982 ; 247: 1007-11$.

\section{Payments to doctors and the} responsibilities of ethics committees

SIR, - We are the two lay-that is, nonmedical-members of an ethics committee that had, some time earlier, unanimously come to the same conclusion as the General Medical Council on the need to disclose to ethics committees payments to doctors from pharmaceutical companies. ${ }^{1}$ We were therefore surprised to read the letter from Dr John G Ball and Dr Eric S Snell (17 December, p 1884).

We are deeply disturbed that both the General Medical Services Committee and the Association of the British Pharmaceutical Industry, by rejecting the GMC recommenda- 
tion, should wish to conceal from ethics committees all information regarding payments by the industry to a doctor taking part in a research project.

In our view such payments are unquestionably relevant to the proper consideration, from an ethical standpoint, of a research project involving drugs and should therefore be revealed to the ethics committee. We cannot accept that "financial relations between doctors and pharmaceutical companies in these circumstances are outside the remit of ethics committees."

Although we do not think that an ethics committee would wish "to discuss and rule on the exact amount that is appropriate for a particular study," it would clearly be a matter of concern for those guarding the welfare of patients if a proposed payment was grossly excessive, and at the very least further inquiries of the parties concerned would be justified. It must be wrong that the payer and recipient should be the sole arbiters of what constitutes a reasonable level of payment.

Finally, our attention has been drawn to the report of a working party on clinical trials, dated October 1974, which was set up by the Medico-Pharmaceutical Forum (comprising representatives of the royal colleges and the industry) and chaired by a prominent member of the pharmaceutical industry. Under the heading "Payments" the report states: "the level of payment is relevant and should ... be approved by the ethics committee or equivalent." This recommendation echoes the finding of a WHO scientific group reporting six years earlier on the conduct of clinical trials. ${ }^{2}$

What has happened in the past 10 years to lead the industry to take a wholly opposite view? We earnestly hope that the ABPI and the BMA will revert to the earlier and far more socially responsible view expressed by prominent representatives of both the industry and the medical profession.

\section{Institute of Advanced \\ Legal Studies
(University of London), \\ London WC1B 5DR}

London NW5 1PH

KENNETH ROBINSON

' General Medical Council. Professional conduct and discipline: fitness to practise. London: GMC, 1983 : 27.

WHO scientific group. Principles for the clinical
evaluation of drugs. WHO Tech Rep Ser 1968;403 para 4.5 .

SIR,-As a lay member of an ethics committee I should like to take issue with Dr John G Ball and Dr Eric S Snell when they challenge the right of ethics committees to inquire about any payments made to doctors for clinical trials.

In my view it is far from "outside our remit" to review any private arrangement that could possibly cloud the doctor's prime commitment to the patient-however rare any abuse migh be (section 17c of the Royal College of Physicians' working party draft report of March 1983 supports this view). Substantial paymen might also influence the decision to instigate the research project in the first place. As it is quite impossible for a lay person to judge whether or not a trial should be undertaken a all (in relation to all existing research in that area), excessive rewards declared on the protocol might alert one to unjustifiable degress of self interest. Unnecessary trials would most certainly be an ethical issue.

It is also no bad thing that financial arrange- ments between private pharmaceutical companies and employees of the public health service should be open to wider scrutiny. Those who have nothing to hide will no doubt be happy to declare any financial rewards as being entirely justifiable.

JENNIFER Cousins

Selly Park,

Birmingham 29

\section{Convaid: for anyone who is speech} impaired?

SIR,-The BMF (19 November, inside back cover), in common with other journals for the medical and paramedical professions and for the lay, has carried advertisements for Convaid, the speech aid developed by Professor $Z M$ Albes of Watchme Ltd. With Convaid, it is said, "Anyone who is speech impaired can converse and be easily understood." This contention appears to derive from a belief that impairment of speech has no other cause than impairment of motor function in speech organs, and is oblivious of the whole of aphasiology.

Convaid is of potential value to the dysarthric or dysphonic patient who has intact language, perceptual, and other higher cerebral functions, relatively unimpaired vision, and full or nearly full use of at least one arm. It may have a place among other speech aids offered to patients after expert assessment of need-a service specifically for which the Department of Health and Social Security funds six Communication Aids Centres throughout the country.

It would be a great pity, and an ultimate disservice to these patients, if overenthusiastic marketing claims were to bring Convaid into disrepute. This seems likely to happen as patients, to whom it is advertised direct, buy it without the benefit of good advice. Unfortunately, Professor Albes herself seems to have difficulty understanding this.

Department of Neurology

TIMOTHY STEINER

Department of Speech Therapy

Alison PerRy

DHSS Communication Aids Julia le Patourel Centre

Charing Cross Hospital,

London W6 8RF

***The manufacturers reply below.-ED, $B M f$.

SIR,-Professor Albes is currently working in the United States, but we are grateful for the opportunity to reply to Dr Steiner's letter.

We agree that our initial advertising was open to misinterpretation and apologise for the overenthusiasm of our advertising agents. We must point out, however, that so far we have advertised only in medical and paramedical journals and the response has been very positive. We have not advertised direct to patients as intimated in Dr Steiner's letter, and when we have inquiries from the general public after television coverage we have always suggested that the person inquiring consult his or her therapist or medical adviser. Even when this advice is not followed, Convaid will be supplied on a trial basis.

Dr Steiner and his colleagues state that
Convaid needs the full or nearly full use of at least one arm. Convaid's full capability is not yet understood; it is programmed to take external accessories and so far we have developed a key scanning device. Other accessories to suit people with limited movement may be able to be adapted to plug into Convaid. This is another aspect that we are currently researching.

Convaid has two related, but from the general public's viewpoint, different roles. Firstly, it was designed as an aid to the therapist and, secondly, simply as a means of communication.

We are sure that the aid centres, which will shortly all receive a number of Convaids funded by the DHSS, will be able to advise us as to the program requirements of the patients brought to them for assessment, as indeed they advise the patients on the most suitable aids. This feedback and cooperation is essential if the full potential and understanding of reprogrammable electronic aids is to be developed.

Frank WolfF Managing Director

Convaid Ltd,

East Sussex BN21 3YA

\section{Head injuries in adults}

SIR,-It is now being proposed that a negative rather than a positive appearance on a skull $x$ ray film may be the more important finding because negative appearances will help to reduce unnecessary admissions after mild head injury. Dr G J de Lacey and Dr B K Wignall (19 November, p 1546) suggest that all patients with mild head injury should undergo $x$ ray examination (this presumably will include the $40 \%$ who do not undergo this examination at present) and that those with a skull fracture should be admitted for observation and those without should be sent home. There are major obstacles to this proposal.

Firstly, there is a widespread assumption that all skull fractures can be detected by radiography, but most radiologists know that this is not so. A carefully controlled study using skull $x$ ray films to locate 18 previously induced occipital and temporoparietal fractures found that six radiologists (three with more than 10 years' experience) failed to detect a fracture in $41(38 \%)$ of 108 instances where a fracture was known to be present. ${ }^{1}$ The problem is further complicated because the casualty officers in the Royal College of Radiologists' multicentre study failed to identify $30 \%$ of skull fractures detected by the radiologist. ${ }^{2}$

Secondly, we have looked at the savings that might be achieved if a normal skull radiograph were used to "avoid" the unnecessary admission for overnight observation of a patient with mild head injury. ${ }^{2}$ We found that 3328 patient radiographs were required to "avoid" 196 admissions at a cost of $£ 254$ per admission avoided (skull $x$ ray examination $£ 15$ per patient). The cost of overnight observation is unlikely to be more than $£ 75$.

Thirdly, one quarter of adults, ${ }^{3}$ and an even higher proportion of children, ${ }^{4}$ who develop intracranial haematoma do not have a skull fracture. If the skull radiograph is thought to show no fracture such patients may be falsely reassured that everything is normal.

There are clearly clinical, technical, and 